\title{
Carbon emissions and electricity generation modeling in Saudi Arabia
}

\author{
Reema Ghazi Alajmi ${ }^{1}$ (D)
}

Received: 30 April 2021 / Accepted: 30 October 2021 / Published online: 20 November 2021

(c) The Author(s), under exclusive licence to Springer-Verlag GmbH Germany, part of Springer Nature 2021

\begin{abstract}
Fossil fuel electricity generation in Saudi Arabia increased greatly from 1980 to 2017 . This paper aims to quantify the electricity generation effect on the environmental quality of Saudi Arabia and explore the role of energy-efficient technological innovation. A structural time series model (STSM) to estimate long-run elasticities and logarithmic mean Divisia index (LMDI) is employed. The results showed that variables (GDP, electricity generation, and population) have a significant effect on carbon dioxide $\left(\mathrm{CO}_{2}\right)$ emissions. Also, the underlying energy demand trend (UEDT) showed an upward slope for the entire period, which suggests that over the study time there is no improvement in energy efficiency. In decomposing the factors for carbon emissions growth in Saudi Arabia, the findings of applying additive LMDI analysis showed a 1377.56 million tonne (MT) increase in $\mathrm{CO}_{2}$ emissions from the three factors between 1980 and 2017 in the country. The results of additive decomposition showed that the primary factor that drives the carbon emissions growth in Saudi Arabia was the structure effect. Saudi Arabian policymakers could make more informed decisions regarding electricity generation by focusing on increasing energy efficiency and demanding strict environmental regulations to contribute to sustainable economic growth.
\end{abstract}

Keywords Carbon emissions · Structural time series model (STSM) · Underlying energy demand trend (UEDT) · Logarithmic mean Divisia index (LMDI) approach · Electricity generation

\section{Introduction}

Global warming and environmental degradation caused by rising emission levels of carbon dioxide $\left(\mathrm{CO}_{2}\right)$ affect life on Earth. The global energy demand is increasing rapidly, driven by growth in economies and population. Despite a high oil consumption providing the basis for economic activity and human wellbeing, it simultaneously is contributing to environmental degradation. This has resulted in a global shift toward a low-carbon energy system, considered a fundamental strategy for sustainable development. Saudi Arabian economic growth still depends on oil, even in the electricity sector. Domestic electricity generation has increased drastically in the past four decades, from 20.45 billion ( $\mathrm{kWh}$ ) in 1980 to 355.48 billion (kWh) in 2018 (U.S. energy information administration 2020). According to the US Energy

Responsible Editor: Roula Inglesi-Lotz

Reema Ghazi Alajmi

rajmi@ksu.edu.sa

1 Economics Department, College of Applied Studies and Community Service, King Saud University, P.O. Box 22459, Riyadh 11495, Saudi Arabia
Information Administration, Saudi Arabia ranked 6th in petroleum and other liquids consumption (3328 thousand barrels per day) and ranked 13th in electricity consumption (295 billion kilowatt-hours) in 2017 (U.S. energy information administration 2020). Saudi Arabia's environmental issues are related to dependency on fossil fuel for development and economic growth, and so the country faces a great challenge in finding a suitable path to ensure economic growth and maintain the quality of the environment.

The National Action Plan for Energy Efficiency (2019) stated that Saudi Arabia needs to invest in the efficiency of energy to combat global climate change for two reasons: First, using less energy will reduce emissions. Second, costeffective energy efficiency will lead to environmental advantages and achieve climate goals.

Saudi Arabia was placed 11th in a global ranking of carbon dioxide emissions from fuel combustion in 2018 (IEA 2019). Statistics reveal that carbon dioxide emissions from fossil fuel combustion increased from 97.9 MT in 1980 to 575.47 MT in 2018; see Fig. 1 (BP Statistical Review of World Energy 2020 ). Thus, the policy to reduce carbon dioxide emissions will become more challenging for Saudi Arabia because the country relies on fossil fuel consumption 
in its sectors including electricity generation; this situation motivated the current study. Therefore, it is crucial to determine the environmental impact of electricity generation from fossil fuels for Saudi Arabia. How do these environmental effects vary with key characteristics of the economy, such as the economic activities and population?

Therefore, there are two objectives; the first objective is to quantify the impact of electricity generation on environmental quality along with conventional variables in Saudi Arabia through employing a structural time series model (STSM) to explore the role of energy-efficient technological innovation to protect environmental quality in Saudi Arabia over the period from 1980 to 2017. The second objective is to explore the factors influencing changes in carbon dioxide emissions in Saudi Arabia by using the logarithmic mean Divisia index (LMDI) decomposition method analyses changes in carbon emissions over four decades. To the best of our knowledge, by using these two methods (STSM and LMDI), this study is the first to consider the trends and factors of carbon emissions from electricity generation in Saudi Arabia.

The study is organized as follows. "Literature review" presents a literature review. The econometric framework employed and data are given in "Methodology." "Empirical results and discussions" presents the structural time series results and the logarithmic mean Divisia index (LMDI) decomposition results and discussions. Finally, "Conclusion and policy implications" is the conclusion and policy implications.

\section{Literature review}

Many studies have discussed and examined the relationship between economic growth, energy, and environmental pollution. In this study, we will highlight some of these, particularly studies related to $\mathrm{CO}_{2}$ emissions, energy, and electricity generation.

For energy modeling, several studies have employed the STSM method. Hunt et al. (2003a, b) analyzed the demand for aggregate energy for different sectors in the UK using the STSM approach. They found that trends reflect other factors besides technical progress such as changes in the structure of economic and consumer tastes. Hunt and Ninomiya (2003) examined oil demand in the transport sector using the STSM method with quarterly data for Japan and the UK. Their results show that the suitability of stochastic trends is better than traditional deterministic ones. Also, Broadstock and Hunt (2010) estimated the demand relationship for oil transport using the STSM. Their findings have important implications for policymakers who want to reduce growth in transport oil consumption and its emissions in the UK.

Other studies have used the STSM method in the electricity sector, such as Amarawickma and Hunt (2008), to forecast electric demand in Sri Lanka. They employed the STSM technique to forecast up to 2025. Also, Dilaver and Hunt (2011) forecast the demand for industrial electricity in Turkey by using the STSM approach and estimate UEDT to provide information about unobserved components that affect energy demand. Similarly, Atalla and Hunt (2016) employed the STSM method for the Gulf Cooperation Council (GCC) countries to explore the drivers of residential electricity demand. Their results suggested that there is a need to improve the efficiency of appliances and raise awareness to reduce electricity consumption. Javid and Qayyum (2014) investigated the relationship among economic activity and electricity consumption in four sectors of Pakistan over the period 1972 to 2012 using the STSM method. The results of UEDT showed that there are no improvements in energy efficiency in these sectors. Atalla et al. (2018) estimated gasoline demand using the STSM method for Saudi Arabia and found that the government cannot limit gasoline consumption growth in the future because of price inelasticity. Thus, they need to increase energy awareness and improve energy efficiency.

In terms of carbon emission studies, Alkhathlan and Jaivd (2015) used the STSM approach to expose the UEDT for the emissions of carbon to analyze the impact of total oil consumption on the environmental quality in Saudi Arabia from 1971 to 2013. Their findings showed that the models have a nonlinear and stochastic trend, so growth in $\mathrm{CO}_{2}$ emissions. Javid and Khan (2020) examined the role of technological innovations to protect environmental quality (by reducing emissions of $\mathrm{CO}_{2}$ ) in the top five greenhouse gas-emitting countries using the STSM approach for data from 1971 to 2016. The findings show that energy consumption positively affects $\mathrm{CO}_{2}$ emissions for all five countries. A recent study by Alarenan et al. (2020) modeled industrial energy demand in Saudi Arabia using STSM from 1986 to 2016. Based on the elasticity long-run results, as economic activity increases in Saudi Arabia, the demand for industrial energy will continue to grow in the next decades.

Liu et al. (2007) examined the growth of industrial $\mathrm{CO}_{2}$ emissions for 36 industrial sectors in China from 1998 to 2005 using the LMDI approach. The results showed that there are two main contributors driving the growth of industrial $\mathrm{CO}_{2}$ emissions in China: industrial activity and real energy intensity because of the increase in electricity use. Also, $\mathrm{Xu}$ et al.(2014) analyzed factors that impact $\mathrm{CO}_{2}$ emissions in China from 1995 to 2011, using LMDI additive decomposition to decompose $\mathrm{CO}_{2}$ emissions for energy consumption into factors, such as energy structure, energy intensity, and population effects. The results display that the major contributors to $\mathrm{CO}_{2}$ emissions are electricity production, petroleum processing, and others. Furthermore, Kim (2017) used the LMDI decomposition to analyze factors that affect energy consumption in the manufacturing sector 
in Korea from 1991 to 2011. The decomposition showed that the reason behind increasing energy consumption is the activity effect. Daldoul and Dakhlaoui (2018) evaluated the factors that impact the carbon emissions in the transportation sector in Tunisia. They used the LMDI decomposition method for the period from 1991 to 2016. They found that the main factor behind carbon emissions growth is the transport sector. Tu et al. (2019) employed LMDI decomposition to investigate the changes in carbon emissions of the transport sector from 1960 to 2001 in different cities. They suggested some effective strategies to reduce carbon emissions, such as rational land use, fuel economy policies, and the development of public transport. Furthermore, there are studies using ARDL techniques to estimate the relationship between $\mathrm{CO}_{2}$ emissions, energy consumption, GDP, and other variables for several countries including Saudi Arabia, such as Begum et al. (2015), Mert and Bölük (2016), Samargandi (2017), and Balaguer and Cantavella (2018). They found that GDP contributed to $\mathrm{CO}_{2}$ emissions. Baek and Kim (2013), Bouznit and Pablo-Romero (2016), and Ahmad et al. (2016) found that energy consumption positively affects $\mathrm{CO}_{2}$ emissions.

Other studies examined the relationship between energy use and emissions using different methods. Ali et al. (2017) used the Bilan Carbone model-scenario-based modeling to analyze reduced energy use and carbon emissions for the Bangkok Metropolitan Area in Thailand. The results show that the $\mathrm{CO}_{2}$ emissions in the city will decrease by $50 \%$ through following the optimal solutions provided under the 2050 low-carbon scenario compared to the business-as-usual scenario. Also, Ali et al. (2018) investigated the relationship between income, education, and carbon footprint at the University of Agriculture Faisalabad, using the ordinary least squares (OLS) approach. Findings indicated that the carbon footprint increased by 1.15 million tonnes per year when faculty members increased by one. Thus, the attitude toward environmental pollution should be changed, and awareness should be created to reduce the carbon footprint on campus to be environmentally friendly through promoting public transportation and reducing car use. Also, Ali et al. (2019) examined different possibilities for cost/benefit analysis for the mitigation approach of carbon emission levels in the Lahore Metropolitan Area (marked by a high population creating huge energy demands and carbon emissions) of Pakistan using the multi-criteria decision analysis (MCDA) approach and the Bilan Carbone method for energy environment modeling. Their results showed no evidence of renewable energy use, and mitigation analysis of different sectors showed that carbon emissions would be reduced by $50 \%$ in 2050 under the low-carbon scenario.

Recently, Chontanawat et al. (2020) decomposed the changes in carbon emissions related to the industrial sector by employing an LMDI approach for Thailand from 2005 to 2017. Their results reveal that the energy intensity of individual industries led to increased $\mathrm{CO}_{2}$ emissions and a structural effect reducing $\mathrm{CO}_{2}$ emissions. Quan et al. (2020) found that economic growth is the main factor promoting carbon emissions, followed by the positive impact of population size and energy structure using LMDI decomposition in China's logistics industry from 2000 to 2016 . Raza and Lin (2020) apply the LMDI technique to detect the influencing variables on $\mathrm{CO}_{2}$ emissions growth in Pakistan's transport sector covering the period 1984-2018, showing that the economic growth effect increases $\mathrm{CO}_{2}$ emissions. Another study in Pakistan by Yasmeen et al. (2020) assessed $\mathrm{CO}_{2}$ emissions from 1972 to 2016 through employing the LMDI approach. Their results indicated an economic development factor behind increasing per capita carbon emissions, while restraining factors for per capita carbon emissions are energy structure and energy efficiency. In terms of energy consumption, Alarenan et al. (2020) applied the LMDI approach to decompose the growth in consumption of industrial energy for Saudi Arabia from 1986 to 2016. The LDMI findings revealed that the two effects (activity and structure) have roles in driving the demand for industrial energy. Akyürek (2020) used LMDI for the energy consumption growth of Turkish manufacturing industries from 2005 to 2014, and the results show that the activity effect has a significant influence on energy consumption, while other effects are small. Ali et al. (2021) recently found reduced pollution emissions resulting from the countrywide lockdown to minimize the spread of the COVID-19 virus in Pakistan due to the turnoff in energy consumption by human and industrial activities. The findings showed that there is a need for appropriate management of transportation systems, land use expansion, industrial emissions, and the use of renewable energy.

The above studies used several methods to examine the energy consumption and emissions problems, but none of them examined changes in Saudi Arabia using the STSM or LMDI approach, a gap we aim to fill. The contributions of this study to current literature are on electricity generation and carbon emissions by estimating the impact of electricity generation on carbon emissions, capturing the effect of exogenous factors, such as energy efficiency, and highlighting the factors behind the growth in carbon emissions in Saudi Arabia. This analysis will help policymakers to identify the contribution of electricity production to environmental degradation. Then, they can take steps toward raising energy efficiency in this sector.

\section{Methodology}

This study will employ both the structural time series models (STSM), also known as unobserved components models, and decomposition analysis using the logarithmic mean Divisia 
index (LMDI) method. To better understand the impact of electricity generation on environmental quality, we employ the LMDI decomposition analysis to quantify the contributions to a change in a variable or aggregate economic, energy, or environmental indicator (Ang and Zhang 2000). The STSM will estimate the long-run relationships between GDP, electricity generation, population growth, other exogenous factors, and carbon emissions in Saudi Arabia, while the decomposition approach will estimate the factors of the growth in emissions of carbon over four decades.

\section{Data}

Generally, in the energy-environment literature, economic growth, population, and electricity generation are important variables that contribute to carbon emissions besides other factors. Therefore, the carbon dioxide emissions $\left(\mathrm{CO}_{2}\right)$ is a function of gross domestic product GDP (Y), fossil fuel electricity generation (EOC), population growth (POP), and UEDT, which captures the impact of exogenous factors. Annual time-series data from 1980 to 2017 for Saudi Arabia will be used in this study for analyzing the relationship between electricity generation and environmental quality in the country. $\mathrm{CO}_{2}$ emissions data were obtained from the BP World Energy (BP Statistical Review of World Energy 2019) online database. The data for fossil fuel electricity generation were obtained from the Energy Information Administration (EIA 2020). Data on GDP and population growth were obtained from World Development Indicators (World Bank 2020).

The data of fossil fuel electricity generation is shown in Fig. 1, illustrating the strong general growth in Saudi Arabian electricity production through 1980 to 2018, but a high growth starting from 2011 then became steady in the last two years. Also, Fig. 1 shows total $\mathrm{CO}_{2}$ emissions from different sources, with an increase from 97.91 MT in 1980 to 575.47 MT in 2018. The previous graphs indicate that the increasing electricity generation using fossil fuels will produce more carbon emissions, which in turn affects the environment quality adversely. Figure 2 illustrates the total GDP trend of the oil sector and nonoil sector (private and government sectors, and import duties), showing a continuous rise during the period from 1980 to 2018.
Fig. 1 Saudi Arabia fossil fuel electricity generation by billion $\mathrm{kWh}$ and total $\mathrm{CO}_{2}$ emissions by million tonnes (1980-2018). Source: U.S. energy information administration 2020 and BP Statistical Review of World Energy 2020

Fig. 2 Saudi Arabia total GDP; oil GDP and non-oil GDP by billion Riyals (SR) (19802018). Source: SAMA 2021
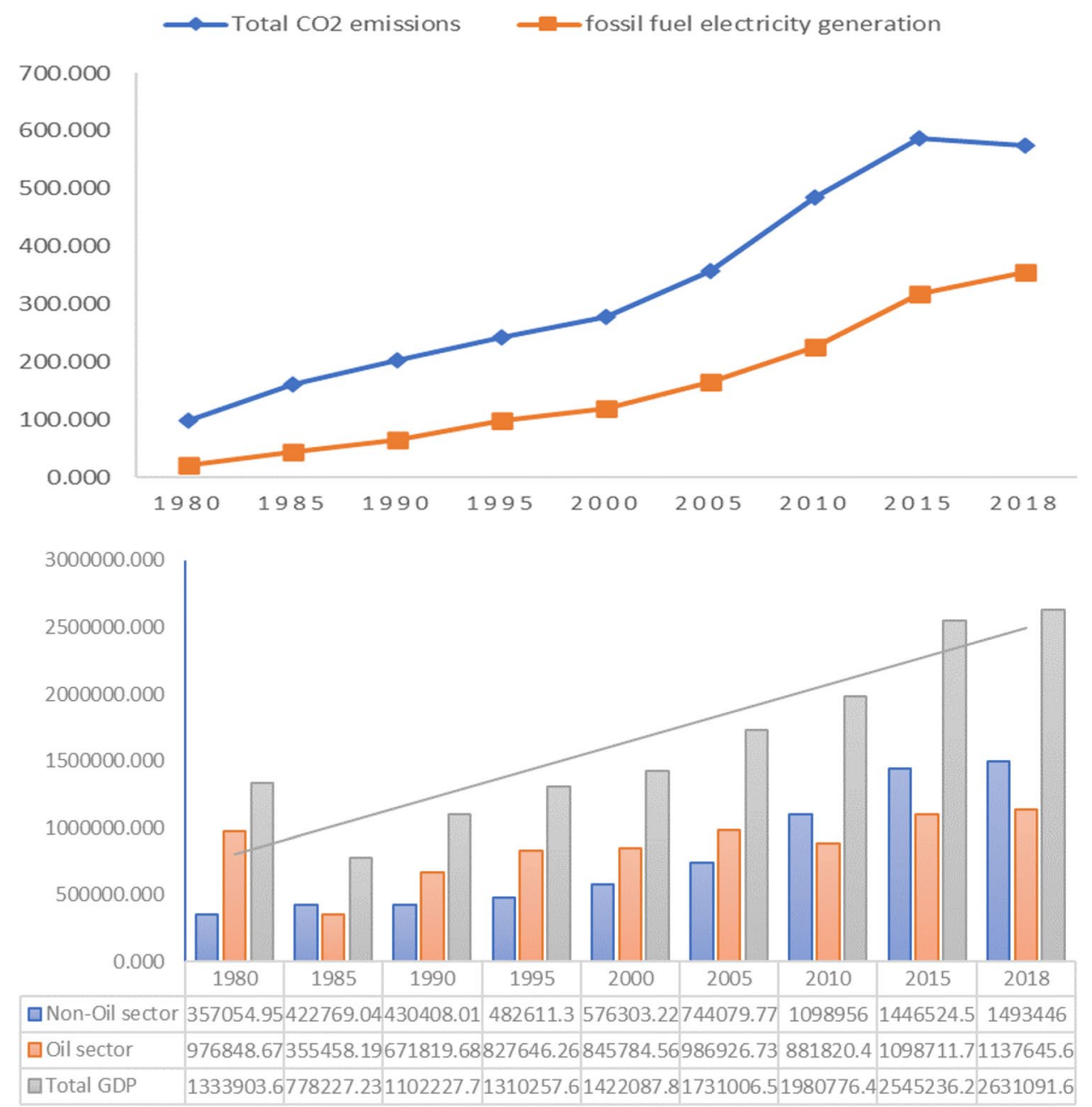


\section{The structural time series model (STSM) and the UEDT concept}

The STSMs developed by Harvey (1990) and the underlying energy demand trend (UEDT) proposed by Hunt et al. (2000, 2003a, b) are to be modeled stochastically. Simply, the STSM approach produces a better forecast and gives a better fit. This model uses stochastic trends (to pick up changes that cannot be explicitly measured in habits and tastes) with explanatory variables (Harvey 2006). Therefore, to evaluate the impact of energy-efficient technological innovation in reducing carbon emissions, we need to use a methodological framework that can capture the other unobservable factors. Thus, we employed the STSM model to estimate the energy-efficient technological innovation effect in reducing $\mathrm{CO}_{2}$ emissions.

Following the studies that used the STSM approach such as Dilaver and Hunt (2011), Javid and Khan (2020), and Alarenan et al. (2020), carbon emission is modeled as a function of

$\mathrm{CO}_{2}=f(Y, E O C, P O P, U E D T)$

where $\mathrm{CO}_{2}$ is carbon emissions in million tonnes (MT); $\mathrm{Y}$ is gross domestic product (GDP) in billion Saudi Riyals (SR); EOC is fossil fuel electricity generation in billion kilowatthours $(\mathrm{kWh})$; POP is population growth, and UEDT is underlying energy demand trend for $\mathrm{CO}_{2}$ emissions, which captures the impact of energy-efficient technological innovation on carbon emissions growth, as exogenous factors.

The dynamic autoregressive distributed lag model (ARDL) specification has been used for estimation as follows: interventions on specific dates of the estimation period. By these interventions, the condition of normality of the auxiliary residuals can be retained when required (Harvey and Koopman 1992). Based on Dilaver and Hunt (2011), the UEDT can be written as below:

$U E D T=\mu_{t}+$ irregular intervention + level interventions + slope interventions

Equations (2), (3), and (4) are estimated by maximum likelihood and the Kalman filter. Diagnostic tests and checking the consistency of the estimated parameters must be applied to assess the suitability of the estimated model. The software package STAMP 8.30 (Koopman et al. 2007) is used to estimate our model, and the study results are given in "Empirical results and discussions."

\section{The LMDI decomposition approach}

Ang et al. (1998) introduced a new method by factorizing changes in gas emissions or energy demand using a decomposition method over time. This approach gives perfect decomposition and could be generally employed in energy and environmental decomposition studies. Ang (2005) presented a practical guide for LMDI for both multiplicative and additive decomposition along with the general formulation process and examples. Also, Ang (2015) provided a strong foundation for the implementation of the LMDI decomposition method by presenting eight models in addition to providing guidelines on the choice between these eight models to assist researchers in the application. Therefore, studies of emission and energy widely use the index decomposition analysis (IDA) as an analytical component. This use has attracted policymakers to follow energy efficiency trends

$c o_{t}=\alpha_{1} c o_{t-1}+\alpha_{2} c o_{t-2}+\beta_{0} y_{t}+\beta_{1} y_{t-1}+\beta_{2} y_{t-2}+y_{0} e o c_{t}+y_{1} e o c_{t-1}+y_{2} e o c_{t-2}+\delta_{0}$ pop $_{t}+\delta_{1}$ pop $_{t-1}+\delta_{2}$ pop $_{t-2}+U E D T_{t}+\varepsilon_{t}$

where $c o_{t}, y_{t}, e o c_{t}$, and pop $_{t}$ are the natural logarithms of $\mathrm{CO}_{2}, \mathrm{Y}, \mathrm{EOC}$, and POP in year $t$. A 2-year lag is employed based on the Akaike information criterion (AIC) after eliminating the insignificant variables from the model.

The UEDT $\left(\mu_{t}\right)$ consists of level and slope components. $\mu_{t}$ is supposed to have the following process:

$$
\begin{aligned}
& \mu_{t}=\mu_{t-1}+\beta_{t-1}+\eta_{t} ; \eta_{t} \sim N I D\left(0, \sigma_{\eta}^{2}\right) \\
& \beta_{t}=\beta_{t-1}+\xi_{t} ; \xi_{t} \sim N I D\left(0, \sigma_{\xi}^{2}\right)
\end{aligned}
$$

where $\mu_{t}$ and $\beta_{t}$ represent the level and the slope of the trend, respectively. $\eta_{t}$ and $\xi_{t}$ with zero means and variances $\sigma_{\eta}^{2}$ and $\sigma_{\xi}^{2}$ are the uncorrelated mutual white noise disturbance terms. Information about significant breaks and structural changes can be given by irregular, slope, and level
(Ang, 2015). This study uses the additive logarithmic mean Divisia index (LMDI) decomposition approach to assess the change in carbon emissions between a reference year, denoted by the superscript 0 , and an end year, denoted by the superscript $\mathrm{T}$, into additive components that call factors. In additive decomposition analysis, the aggregate change (the arithmetic or difference change) and decomposition results are given in a physical unit (Ang 2015). However, by implementing the additive LMDI decomposition approach suggested by Ang et al. (1998) for one sector, which is the electricity sector, the carbon emissions can be formulated as follows:

$\Delta C_{t o t}=C^{T}-C^{0}=\Delta C_{a c t}+\Delta C_{s t r}+\Delta C_{p o p}$

The subscript tot represents the total change in carbon emissions, and the terms on the right-hand side of the equation give the effects linked to the respective factors. The term $\Delta C_{a c t}$ 
Table 1 Estimated coefficients of preferred models

\begin{tabular}{|c|c|c|}
\hline Variables & ARDL & $t$-test \\
\hline \multicolumn{3}{|c|}{ Estimated coefficients } \\
\hline$\beta_{0}$ & 0.097 & 1.816 \\
\hline$\beta_{1}$ & - & - \\
\hline$\beta_{2}$ & - & - \\
\hline$\gamma_{0}$ & 0.797 & 7.176 \\
\hline$\gamma_{1}$ & - & - \\
\hline$\gamma_{2}$ & 0.490 & 5.242 \\
\hline$\delta_{0}$ & 0.504 & 7.394 \\
\hline$\delta_{1}$ & -0.775 & -6.716 \\
\hline$\delta_{2}$ & 0.417 & 7.267 \\
\hline \multicolumn{3}{|c|}{ Estimated long-run coefficients } \\
\hline GDP & 0.097 & \\
\hline $\mathrm{EOC}$ & 1.288 & \\
\hline POP & 0.145 & \\
\hline \multicolumn{3}{|l|}{ Hyper-parameters } \\
\hline Level & 0.000 & \\
\hline Slope & 0.000 & \\
\hline Irregular & 0.00026 & \\
\hline \multicolumn{3}{|l|}{ Interventions } \\
\hline Irregular 1994 & 0.088 & 4.823 \\
\hline Level 1990 & 0.138 & 6.314 \\
\hline Level 1986 & -0.102 & -5.431 \\
\hline \multicolumn{3}{|c|}{ Components of UEDT 2017} \\
\hline Level $(\mu)$ & -1.0199 & \\
\hline Slope $(\beta)$ & -0.0339 & \\
\hline
\end{tabular}

is called activity effect and measures the impact of GDP on change in carbon emissions. The term $\Delta C_{s t r}$ is called structure effect and measures the impact of electricity generation on change in carbon emissions. The term $\Delta C_{p o p}$ is defined to be the population effect and measures the impact of population growth on change in carbon emissions. Therefore, we can study changes in carbon emissions by determining the changes in three different factors: overall GDP (activity effect), electricity generation (structure effect), and population growth (population effect). In order to estimate the effect of the three factors, the formulas of the additive LMDI approach are adopted from Ang (2005) and presented in Eqs. (7), (8), and (9):

$$
\begin{gathered}
\Delta C_{a c t}=\sum \frac{C^{T}-C^{0}}{\ln C^{T}-\ln C^{0}} \ln \left(\frac{C_{a c t}^{T}}{C_{a c t}^{0}}\right) \\
\Delta C_{s t r}=\sum \frac{C^{T}-C^{0}}{\ln C^{T}-\ln C^{0}} \ln \left(\frac{C_{s t r}^{T}}{C_{s t r}^{0}}\right)
\end{gathered}
$$

$\Delta C_{i n t}=\sum \frac{C^{T}-C^{0}}{\ln C^{T}-\ln C^{0}} \ln \left(\frac{C_{p o p}^{T}}{C_{p o p}^{0}}\right)$

The LMDI becomes the preferred method for decomposition analysis because its results give a perfect decomposition and do not produce any unexplained residuals. Also, it simplifies the result interpretation, as noted by Ang (2005, 2015).

\section{Empirical results and discussions}

\section{ARDL model estimation results}

The preferred estimated equation is

$c o_{t}=0.0997 y_{t}+1.288 e^{2 o c_{t}}+0.145$ pop $_{t}+U E D T_{t}$

where $U E D T_{2017}=-1.018$. Table 1 presents the estimated coefficients of the preferred model in detail, and Table 2 shows the details of diagnostic tests for residuals and auxiliary residuals. Serial correlation, non-normality, and heteroscedasticity for residuals of the estimated equation are tested. Diagnostic tests were generated by the STSM approach, which includes p.e.v. (the prediction error variance), AIC (Akaike information criterion), and the coefficients of determination $\left(R^{2}\right.$ and $R_{d}^{2}$ ) measuring goodnessof-fit. Normality (corrected Bowman-Shenton), Kurtosis, and Skewness are error normality statistics. Normality is approximately distributed as $\chi^{2}(2)$, and Kurtosis and Skewness roughly are distributed as $\chi^{2}(1)$ and $\chi^{2}(1)$, respectively.

Table 2 Diagnostic tests

\begin{tabular}{ll}
\hline Variables & \\
\hline Goodness of fit & \\
P.E.V & 0.000185 \\
AIC & -7.966 \\
$R^{2}$ & 0.9994 \\
$R_{d}^{2}$ & 0.9428 \\
LR test & 101.244 \\
Residuals diagnostic & \\
Std error & 0.0136 \\
Normality & 0.702 \\
$H(h)$ & $H(8)=0.45$ \\
$r(1)$ & -0.299 \\
$Q(6,6-2)$ & 6.75 \\
$r(6)$ & -0.087 \\
Auxiliary residuals & \\
Normality - irregular & $2.021] 0.364[$ \\
Normality - level & $1.830] 0.401[$ \\
Normality - slope & $1.008] 0.6041[$ \\
Prediction failure Chi2 (8) & $3.5496] 0.8953[$ \\
Cusum $t(8)$ & $-0.4941[1.3655]$ \\
\hline
\end{tabular}

The number between brackets is $p$ values 
$H(8)$ is the test for heteroscedasticity, approximately distributed as $F(8,8) . r(1)$ and $r(6)$ are the serial correlation coefficients at the equivalent residual lags, approximately normally distributed. $Q(6,6-2)$ is the Box-Ljung statistic based as $\chi^{2}$. Predictive failure statistic is distributed as $\chi^{2}$ (8), and Cusum is a mean stability statistic distributed as the Student's $t$ distribution, meaning there is a predictive failure test for the last 8 years of the estimation period. Finally, the LR test represents a likelihood ratio test used to determine the deterministic time trend. Table 2 reveals that the model passes all the diagnostic tests, including the additional normality tests for the auxiliary residuals.

Table 1 reports estimated long-run elasticities. The long-run elasticity estimate of $\mathrm{CO}_{2}$ emissions with respect to electricity generation is positive and statistically significant, which means electricity generation has a significant impact on carbon emissions. In other words, for a one percent increase in electricity generation in Saudi Arabia, carbon emissions are increasing by 1.288 in the long run. However, this model also reveals that $\mathrm{CO}_{2}$ emissions are influenced by electricity generation level; this affirms the impact a change in electricity generation can have on carbon emissions. One reasonable explanation behind these results is inefficiency; for example, the electricity appliances are of low efficiency. Another reason behind Saudi Arabia's high use of electricity is the lower price of electricity compared to other countries. Prices in Saudi Arabia reached around 0.069 US dollar/kWh for businesses and 0.048 US dollar/ $\mathrm{kWh}$ for households in 2019 , compared to the average price of electricity in the world which is 0.14 US dollar $/ \mathrm{kWh}$ for the same period (Global Petrol Prices 2020). Our result is consistent with studies that found a significant relationship between $\mathrm{CO}_{2}$ emissions and energy consumption, such as Begum et al. (2015), Alkhathlan and Javid (2015), Mert and Bölük (2016), Samargandi (2017), Balaguer and Cantavella (2018), and Javid and Khan (2020). However, our estimation for the elasticity of electricity generation from oil in the long run (1.28) is similar to Alkhathlan and Javid's (2015) long-run elasticity (1.11).

Also, this study found that the long-run elasticity estimate of $\mathrm{CO}_{2}$ emissions with respect to GDP is positive and statistically significant, which means GDP has a significant impact on carbon emissions. For a one percent increase in GDP in Saudi Arabia, carbon emissions are increasing by 0.097 in the long run. This result is consistent with previous studies that found GDP positively impacting carbon emissions, such as Baek and Kim (2013), Bouznit and PabloRomero (2016), Ahmad et al. (2016), Alkhathlan and Javid (2015), and Javid and Khan (2020).

Additionally, the long-run elasticity of $\mathrm{CO}_{2}$ emissions with respect to population is positive and significant. In other words, there is a relationship between carbon emissions and population growth in the long run. This indicates that for a one percent increase in population growth of Saudi Arabia, carbon emissions are increasing by 0.145 in the long run. This reflects insufficient awareness of environmental issues and reflects the importance of the initiative of the Saudi Energy Efficiency Center in launching the national campaign for energy to raise awareness of the rationalization of electricity consumption (Efficiency 2020). Table 2 presents the LR test, which does not reject the stochastic specification of the underlying trend in $\mathrm{CO}_{2}$ emissions in the data. The UEDT will capture exogenous factors including energy efficiency; thus, UEDT should reflect changes in energy efficiency. The estimated UEDT for the preferred model consists of stochastic level and slope. Figure 3 illustrates that the estimated UEDT is increasing over the study period, which suggests a lack of procedures to protect environmental quality, such as technical improvement to raise energy efficiency and energy-efficient appliances. For keeping the normality of residuals and auxiliary residuals level, interventions in 1986 and 1990 and irregular intervention in 1994 were required.

From these findings, policymakers could reform energy efficiency regulations through demanding strict
Fig. 3 The estimated UEDT for the preferred model

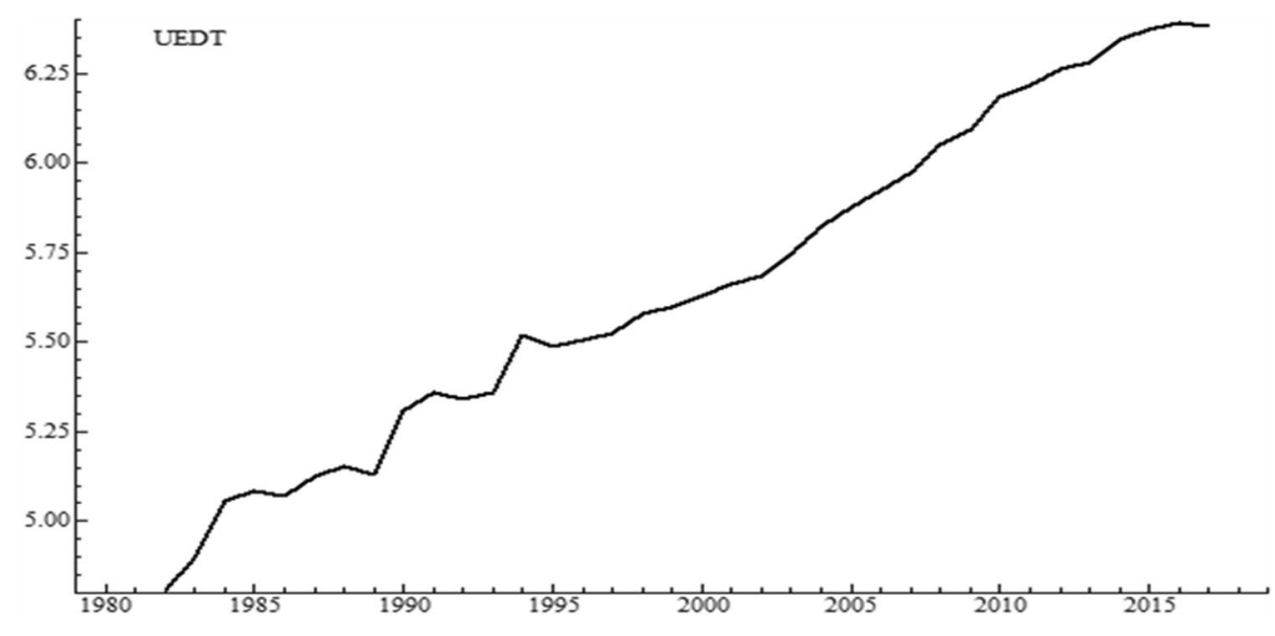


environmental regulation and increasing economic efficiency in order to maintain environmental quality. Also, the population is increasing the consumption of electricity by using household appliances such as cooling, lighting, and heating. Thus, improving the efficiency of appliances via reducing energy consumption will reduce emissions (Cooper 2017).

\section{LMDI approach results}

By employing the additive LMDI approach, we decompose the change in carbon emissions into three factors: an activity effect, a structure effect, and a population effect. For more details on additive LMDI methodology, see Ang (2005). Based on LMDI, we can analyze what factors have the greatest impact on the change in Saudi Arabia's carbon emissions over the period 1980-2017. Table 3 presents 1980 as year 0 , 2017 as year T, and the results of decomposition for Eq. (6). From this table, it can be seen that Saudi Arabia's $\mathrm{CO}_{2}$ emissions increased by 1377.56 million tonnes (MT) from 1980 to 2017. The LMDI additive decomposition results show that the structure effect is the main factor that led to an increase in carbon emissions growth of 737.08 (MT), also the population growth effect that led to an increase in carbon emissions by 337.11 (MT). This is followed by the activity effect increasing carbon emissions by 303.37 (MT). The bottom line is the effect that played a significant role in raising emissions of $\mathrm{CO}_{2}$ is the structure effect (electricity generation). Overall, the contributions of the three factors illustrate the importance of changing the current energy efficiency and decreasing the growth in $\mathrm{CO}_{2}$ emissions. Our LMDI result

Table 3 Additive LMDI decomposition results of $\mathrm{CO}_{2}$ emissions: Saudi Arabia from 1980 to 2017 by million tonnes (MT)

\begin{tabular}{llll}
\hline$\Delta C_{\text {tot }}$ & $\Delta C_{\text {act }}$ & $\Delta C_{\text {str }}$ & $\Delta C_{\text {pop }}$ \\
\hline 1377.56 & 303.37 & 737.08 & 337.11 \\
\hline
\end{tabular}

is consistent with some previous studies, such as $\mathrm{Xu}$ et al. (2014), Daldoul and Dakhlaoui (2018), Liu et al. (2007), and Chontanawat et al. (2020) that energy consumption is behind $\mathrm{CO}_{2}$ emissions growth. By contrast, some studies found that the activity effect is the main factor that led to the growth of carbon emissions, such as Quan et al. (2020), Raza and Lin (2020), and Yasmeen et al. (2020).

Figure 4 illustrates the additive decomposition results with the year-to-year change in carbon emissions by million tonnes (MT). It shows that the structure effect (electricity generation) was the largest factor in carbon emissions growth in Saudi Arabia. In other words, the increase in electricity generation was driving the growth in carbon emissions. Other important factors are activity and population effects which led to the increased carbon emissions. The total change of the growth of $\mathrm{CO}_{2}$ emissions in Saudi Arabia reflects the absence of energy efficiency implementation, and that could create more pressure on environmental quality. Figure 5 shows a bar chart for the additive composition results presented in Table 3, which is the same decomposition in Fig. 4 but presents the results of each factor separately over the period 1980-2017. The positive values of the structure effect (electricity generation) reflect the dependence of Saudi Arabia on the production and consumption of fossil fuel production. Another important factor that led to increased carbon emissions is the activity effect which implies that Saudi GDP was driven by fossil fuel demand growth. The next important factor is the population effect which played a role because an increasing population growth causes upward pressure on electricity generation demand, which leads to increased carbon emissions growth. Overall, the decomposition results confirm that during the period of study, Saudi Arabia, by relying on fossil fuel consumption without raising energy efficiency, increased carbon emissions. It is worth noting that the LMDI approach results are consistent with the STSM method results, which are that
Fig. 4 Presentation of the additive decomposition results from year-to-year $\mathrm{MTCO}_{2}$

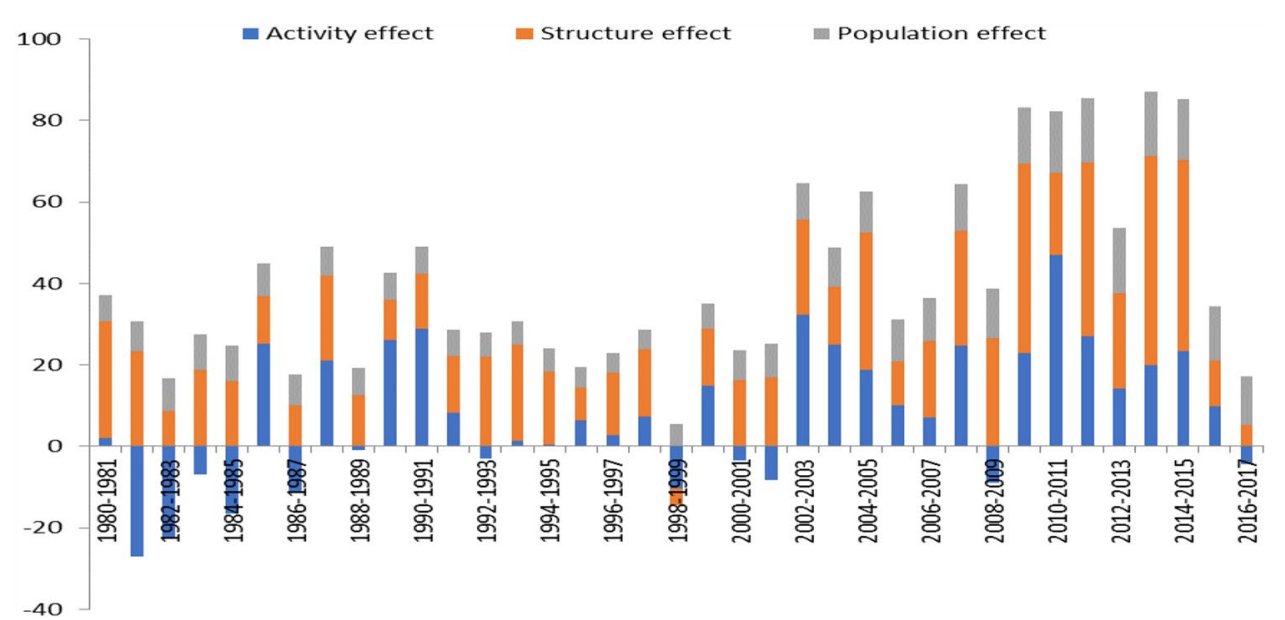




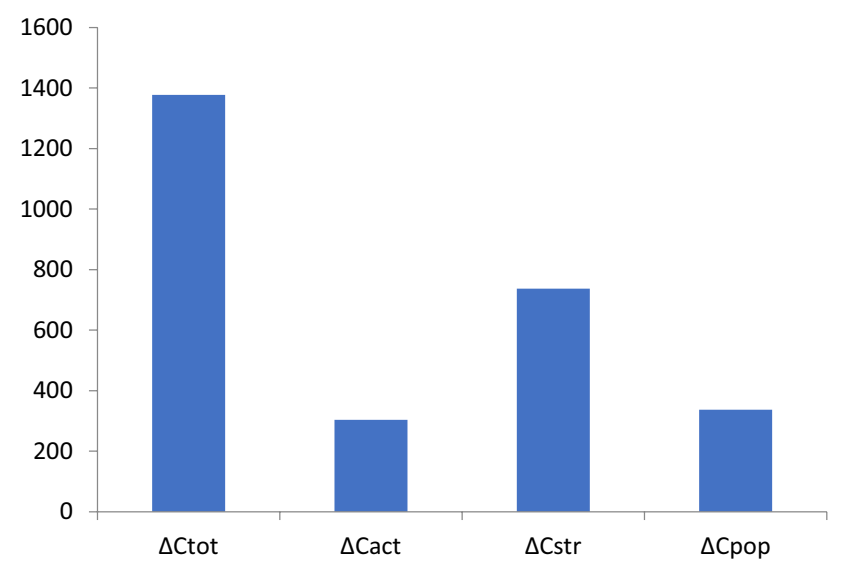

Fig. 5 Additive decomposition presentation results (Table 3) by $\mathrm{MTCO}_{2}$

electricity generation in Saudi Arabia caused a change in carbon emissions growth along with other variables.

It is useful to present the Saudi initiatives to increase energy efficiency, such as the Saudi Energy Efficiency Center (SEEC) to achieve goals such as (1) rationalization of electricity consumption; (2) in 2030, Saudi Arabia is expected to yield an equivalent of 1.5 million barrels of oil per day by employing energy efficiency; (3) the country started in March 2020 the national campaign for energy to raise awareness, through lectures and workshops; and (4) the Saudi Energy Efficiency Program (Efficiency 2020).

\section{Conclusion and policy implications}

This study focuses on the impact of electricity generation in Saudi Arabia on environmental quality from 1980 to 2017. A structural time series model (STSM) was employed in this study to find the estimates and significance levels of the effect of electricity generation on the growth of carbon emissions. This technique also helps the underlying energy demand trend (UEDT) to be modeled stochastically to capture the energy-efficient technological innovation and other exogenous factors. That means a new assessment of the contribution of technological innovation on environmental quality. Moreover, this study also employed additive logarithmic mean Divisia index (LMDI) analysis to assess the factors behind the growth in carbon emissions in Saudi Arabia over four decades.

The estimated econometric model found the long-run elasticities of GDP, electricity generation, and population growth to be $0.097,1.288$, and 0.145 , respectively. The longrun elasticity of GDP suggests that Saudi Arabian carbon emissions will continue to increase when economic activity expands in the future. The long-run electricity generation elasticity proposes that Saudi carbon emissions will continue to grow over the coming decades as electricity generation increases. Thus, Saudi Arabia could increase its electricity productivity by moving toward improving energy efficiency and decreasing the use of oil intensively. The electricity generation elasticity shows that a one percent shift away from using oil in the electricity sector may decrease carbon emissions by 1.288 in the long run. Also, we found that the trend shape is nonlinear and stochastic and has a rising slope for the entire period.

The results of the additive logarithmic mean Divisia index decomposition method showed that the structure effect (electricity generation) was the main factor which increased carbon emissions by 737.08 (MT), followed by the activity effect and population effect, both increasing carbon emissions by 303.37 (MT) and 337.11 (MT), respectively. Our logarithmic mean Divisia index result is in line with some previous studies, that energy consumption is behind carbon dioxide $\left(\mathrm{CO}_{2}\right)$ emissions growth and differs from some studies that found the activity effect as the main factor of carbon emissions, such as Quan et al. (2020), Raza and Lin (2020), and Yasmeen et al. (2020).

These results suggest that energy efficiency is the key; thus, Saudi Arabia needs to invest in technology innovation and raise energy efficiency. To improve energy intensity, new energy-saving equipment or processing technology should be introduced. Also, the government should be expanding research and development on energy efficiency and financing technical support related to this research (Kim 2017). These findings suggest that having better knowledge about factors of growth in carbon dioxide emissions and how they might evolve in the future should enable Saudi policymakers to make more informed decisions with regards to electricity generation, so they can choose suitable strategies to raise energy efficiency and take into account environment quality at the same time. Moreover, if policymakers wish to reduce carbon emissions, but do not want to curtail economic growth, then they need to increase environmental awareness through the education system (Zafar et al. 2020).

As Saudi Arabia has begun energy efficiency programs, future research could look at future energy consumption and carbon dioxide emissions under different scenarios and examine the impact of energy efficiency projects on limiting the growth of carbon emissions.

Acknowledgements The author thanks the Deanship of Scientific Research and RSSU at King Saud University for their technical support.

Author contribution Not applicable.

Data availability The datasets used and/or analyzed during the current study are available from the corresponding author on reasonable request. 


\section{Declarations}

Ethics approval and consent to participate Not applicable.

Consent for publication Not applicable.

Competing interests The authors declare no competing interests.

\section{References}

Ahmad A, Zhao Y, Shahbaz M, Bano S, Zhang Z, Wang S, Liu Y (2016) Carbon emissions, energy consumption and economic growth: an aggregate and disaggregate analysis of the Indian economy. Energy Policy 96:131-143

Alarenan S, Gasima AA, Hunt LC (2020) Modelling industrial energy demand in Saudi Arabia. Energy Econ 85:104554

Ali G, Abbas S, Pan Y, Chen Z, Hussain J, Sajjad M, Ashraf A (2019) Urban environment dynamics and low carbon society: multi-criteria decision analysis modeling for policy makers. Sustain Cities Soc 51:101763

Ali G, Abbas S, Qamer FM, Wong MS, Rasul G, Irteza SM, Shahzad N (2021) Environmental impacts of shifts in energy, emissions, and urban heat island during the COVID-19 lockdown across Pakistan. J Clean Prod 291:125806

Ali G, Anbren S, Bashir MK (2018) Climate mitigation, lowcarbon society, and dynamism. Environ Sci Pollut Res 25:3775-3784

Ali G, Pumijumnong N, Cui S (2017) Decarbonization action plans using hybrid modeling for a low-carbon society: the case of Bangkok Metropolitan Area. J Clean Prod 168:940e951

Alkhathlan K, Jaivd M (2015) Carbon emissions and oil consumption in Saudi Arabia. Renew Sustain Energy Rev 48:105-111

Akyürek Z (2020) LMDI decomposition analysis of energy consumption of Turkish manufacturing industry: 2005-2014. Energy Effic 13:649-663

Amarawickma HA, Hunt LC (2008) Electricity demand for Sri Lanka: a time series analysis. Energy 33:724-739

Ang BW, Zhang FQ, Choi KH (1998) Factorizing changes in energy and environmental indicators through decomposition. Energy 23(6):489-495

Ang BW, Zhang FQ (2000) A survey of index decomposition analysis in energy and environmental studies. Energy 25:1149-1176

Ang BW (2005) The LMDI approach to decomposition analysis: a practical guide. Energy Policy 33:867-871

Ang BW (2015) LMDI decomposition approach: a guide for implementation. Energy Policy 86:233-238

Atalla TN, Hunt LC (2016) Modelling residential electricity demand in the GCC countries. Energy Econ 59:149-158

Atalla TN, Gasim AA, Hunt LC (2018) Gasoline demand, pricing policy, and social welfare in Saudi Arabia: a quantitative analysis. Energy Policy 114:123-133

Baek J, Kim HS (2013) Is economic growth good or bad for the environment? Empirical evidence from Korea. Energy Econ 36:744-749

Balaguer J, Cantavella M (2018) The role of education in the Environmental Kuznets Curve. Evidence from Australian data. Energy Econ 70:289-296

Begum AR, Sohag K, Abdullah SMS, Jaafar M (2015) $\mathrm{CO}_{2}$ emissions, energy consumption, economic and population growth in Malaysia. Renew Sustain Energy Rev 41:594-601

Bouznit M, Pablo-Romero MD (2016) $\mathrm{CO}_{2}$ emission and economic growth in Algeria. Energy Policy 96:93-104
Broadstock DC, Hunt LC (2010) Quantifying the impact of exogenous non-economic factors on UK transport. Energy Policy 38:1559-1565

BP Statistical Review of World Energy (2020) s.l.: s.n

Chontanawat J, Wiboonchutikula P, Buddhivanich A (2020) An LMDI decomposition analysis of carbon emissions in the Thai manufacturing sector. Energy Rep 6:705-710

Daldoul M, Dakhlaoui A (2018) Using the LMDI decomposition approach to analyze the influencing factors of carbon emissions in Tunisian transportation sector. Int J Energy Econ Policy $8(6): 22-28$

Dilaver Z, Hunt LC (2011) Modelling and forecasting Turkish residential electricity demand. Energy Policy 39:3117-3127

Efficiency (2020) Saudi Energy Efficiency Center. Retrieved February 15,2021 , from https://www.seec.gov.sa/en/

Global Petrol Prices (2020) Saudi Arabia electricity prices. [Online] Available at: https://www.globalpetrolprices.com/Saudi-Arabia/ electricity_prices/. Accessed 12 January 2021

Cooper M (2017) Pocketbook savings, macroeconomic growth and other public benefits of energy efficiency appliance standards: benefit-cost analysis of four decades of rules shows they have delivered trillions of dollars of economic value to consumer and the nation. The Consumer Federation of America, Washington, DC

Harvey AC, Koopman SJ (1992) Diagnostic checking of unobservedcomponents time series models. J Bus Econ Stat 10:377-389

Harvey A (2006) Forecasting with unobserved components time series models. In: Andrew Harvey (ed) Handbook of Economic Forecasting, Vol 1, pp 327-412

Harvey AC (1990) Forecasting, structural time series models and the Kalman filter. s.1.:Cambridge University Press, Cambridge

Hunt LC, Judge G, Ninomiya Y (2000) Modelling technical progress: an application of the stochastic trend model to UK energy demand. Surrey Energy Economics Discussion Paper, SEEDS99, Department of Economics, University of Surrey, UK

Hunt LC, Judge G, Ninomiya Y (2003a) Modelling underlying energy demand trends. In: Hunt LC (ed) Energy in Competitive Market: Essays in Honour of Colin Robinson. Edward Elgar, UK, pp 140-174

Hunt LC, Judge G, Ninomiya Y (2003b) Underlying trends and seasonality in UK energy demand: a sectoral analysis. Energy Economics 25(1):93-118

Hunt LC, Ninomiya Y (2003) Unravelling trends and seasonality: a structural time series analysis of transport oil demand in the UK and Japan. Energy J 24:63-96

IEA (2019) CO2 Emissions from Fuel Combustion. Retrieved February 10, 2021, from http://energyatlas.iea.org/\#!/tellmap/1378539487

Javid M, Khan M (2020) Energy efficiency and underlying carbon emission trends. Environ Sci Pollut Res 27:3224-3236

Javid M, Qayyum A (2014) Electricity consumption-GDP nexus in Pakistan: a structural time series analysis. Energy 64:811-817

Kim S (2017) LMDI decomposition analysis of energy consumption in the Korean manufacturing sector. Sustainability 9(2):202

Koopman SJ, Harvey AC, Doornik JA, Shephard N (2007) Structural time series analyser and modeller and predictor-STAMP Version 8, Econometric Software

Liu L, Fan Y, Wu G, Wei Y (2007) Using LMDI method to analyze the change of China's industrial $\mathrm{CO}_{2}$ emissions from final fuel use: An empirical analysis. Energy Policy 35:5892-5900

Mert M, Bölük G (2016) Do foreign direct investment and renewable energy consumption affect the $\mathrm{CO}_{2}$ emissions? New evidence from a panel ARDL approach to Kyoto Annex countries. Environ Sci Pollut Res 23:21669-21681

National Action Plan for Energy Efficiency (2019) Energy efficiency as a low-cost resource. s.l.:Prepared by William Prindle, ICF International, Inc. 
Quan C, Cheng X, Yu S, Ye X (2020) Analysis on the influencing factors of carbon emission in China's logistics industry based on LMDI method. Sci Total Environ 734:138473

Raza MY, Lin B (2020) Decoupling and mitigation potential analysis of $\mathrm{CO}_{2}$ emissions from Pakistan's transport sector. Sci Total Environ $730: 139000$

SAMA (2021) Saudi Central bank 55th Annual Report. Riyadh: Saudi Central bank

Samargandi N (2017) Sector value addition, technology and $\mathrm{CO}_{2}$ emissions in Saudi Arabia. Renew Sustain Energy Rev 78:868-877

Tu M, Li Y, Bao L, Wei Y, Orfila O, Li W, Gruyer D (2019) Logarithmic mean Divisia index decomposition of $\mathrm{CO}_{2}$ emissions from urban passenger transport: an empirical study of global cities from 1960-2001. Sustainability 11:4310

U.S. energy information administration (2020) Retrieved September 15, 2021, from https://www.eia.gov/international/data/world\#/? tl_type $=$ p\&t1_id $=2-A \& p a=0000000000002 \& c t=0 \& o r d=S A \& c=$ ruvvvvvfvtvnvv1 urvvvvfvvvvvvfvvvou20evvvvvvvvvnvvu $\operatorname{vo} \& \mathrm{f}=\mathrm{A}$
World Bank (2020) World development indicators. Online database Retrieved January 10, 2021, from https://databank.worldbank. org/source/world-development-indicators

Xu S, He Z, Long R (2014) Factors that influence carbon emissions due to energy consumption in China: decomposition analysis using LMDI. Appl Energy 127:182-193

Yasmeen H, Wang Y, Zameer H, Solangi YA (2020) Decomposing factors affecting $\mathrm{CO}_{2}$ emissions in Pakistan: insights from LMDI decomposition approach. Environ Sci Pollut Res 27:3113-3123

Zafar MW, Shahbaz M, Sinha A, Sengupta T, Qin Q (2020) How renewable energy consumption contribute to environmental quality? The role of education in OECD countries. J Clean Prod 268:122149

Publisher's note Springer Nature remains neutral with regard to jurisdictional claims in published maps and institutional affiliations. 